\title{
Building reproductive health research and audit capacity and activity in the pacific islands (BRRACAP) study: methods, rationale and baseline results
}

\author{
Alec J Ekeroma ${ }^{1 *}$, Tim Kenealy ${ }^{1}$, Boaz Shulruf ${ }^{2}$, Lesley ME McCowan ${ }^{3}$ and Andrew Hill ${ }^{1}$
}

\begin{abstract}
Background: Clinical research and audit in reproductive health is essential to improve reproductive health outcomes and to address the Millennium Development Goals 4 and 5. Research training, mentoring and a supportive participatory research environment have been shown to increase research activity and capacity in low to middle income countries (LMIC). This paper details the methods, rationale and baseline findings of a research program aimed at increasing clinical research activity and audit in the six Pacific Islands of Fiji, Samoa, Tonga, Vanuatu, Cook Islands and the Solomon Islands.

Method: Twenty-eight clinician participants were selected by the five Ministries of Health and the Fiji National University to undergo a research capacity building program which includes a research workshop and mentoring support to perform research and audit as teams in their country. Data on the participants' characteristics, knowledge and experiences were collected from structured interviews, questionnaires, focus groups, and an online survey. The interviews and the two focus groups were audio-recorded and all replies were analysed in a thematic framework.
\end{abstract}

Results: The 28 participants included 9 nurses/midwives, 17 medical doctors of whom 8 were specialists in reproductive health and 2 other health workers. Most $(24,86 \%)$ were required to perform research as part of their employment and yet 17 (61\%) were not confident in writing a research proposal, 13 (46\%) could not use an electronic spreadsheet and the same number had not analysed quantitative data. The limited environmental enablers contributed to poor capacity with only 11 (46\%) having access to a library, 10 (42\%) receiving management support and 6 (25\%) having access to an experienced researcher. Barriers to research that affected more than $70 \%$ of the participants were time constraints, poor coordination, no funding and a lack of skills.

Conclusion: Building a research capacity program appropriate for the diversity of Pacific clinicians required research evidence and collaborative effort of key stakeholders in the Pacific Islands and the region. The participants had limited research knowledge, skills and experience and would require individualized training and continuous intensive mentorship to realize their potential as clinician researchers for their services in the Pacific.

Keywords: Pacific countries, Clinician researchers, Research capacity building, Research skills, Barriers and enablers of research

\footnotetext{
* Correspondence: alec@pacifichealthresearch.org.nz

'South Auckland Clinical Campus, University of Auckland, Middlemore

Hospital, Auckland, New Zealand

Full list of author information is available at the end of the article
} 


\section{Background}

Health research and clinical audit are fundamental components of functioning health systems as they are important at addressing Millenium Development Goals (MDG) and quality of health service delivery [1-4]. Clinical research and audit are implicit in all health service functions and contributes to the effectiveness and efficiency of health care [5]. Low to middle income countries (LMIC) have a disproportionate lack of resources, capacity and personnel leading to poor research output and utilisation [6,7].

Although there has been agreement by Ministers of Health, accompanied by policy efforts of international agencies such as the World Health Organization, (WHO) to strengthen research system capacity in LMICs $[2,8,9]$ there is evidence that political commitment has not matched the rhetoric as poor research capacity in LMIC persist [10].

There have been rewarding partnerships between funding agencies, research institutions and individuals in high income and LMIC resulting in the generation of successful collaborative models [11-13]. Successful research capacity building $(\mathrm{RCB})$ programs tend to be located at dedicated research institutions [14] and universities although systems and sustainability are often weak where there is no reciprocal local funding [15]. Such RCB programs are commonly aimed at developing research scientists [16] with only a few targeting clinicians [17]. While many agencies have concentrated efforts at developing research systems capacity from top down, an effort should also be made to develop research capacity from the bottom up [18]. Such an approach acknowledges the clinicians role in identifying research priorities at the clinical interface $[19,20]$.

Training clinicians to perform clinical research, in the absence of research scientists, requires a paradigm shift $[21,22]$. Clinicians, who are mostly nurses and doctors, have an advantage as clinical researchers over non-clinical researchers as they are likely to have better understanding of the research questions, are able to collect demographic and patient data, and are more enthusiastic in applying locally derived evidence to patient care [23,24]. There is the view that clinicians performing research make better clinicians [25].

There have been only four quasi- experimental studies with different interventions targeting clinicians in LMIC. Lessons from a funded RCB program of rural general practitioners in Australia failed to demonstrate expected outputs, probably due to the lack of time allocated to research and administration support [26]. Similarly, a RCB for primary care in the United States failed, with evaluators recommending protected time for research and sustained mentoring [27]. On the other hand, in-service training at teaching hospitals in Vietnam was deemed effective and sustainable [20] and an allied health RCB program in Australia was found to be effective in generating research publications [28]. It seems that successful RCB programs include substantial research training, completion of a project supported by mentors [29] and strong scientific leadership [30].

To better understand the nature of individual interventions within a RCB program and the characteristics of the clinician participants required to increase clinical research and audit activity and capacity in LMIC, prospective studies are needed where the literature, professional peers and stakeholders' perspectives guide the shape of RCB programs [31].

\section{A RCB program in reproductive health in the pacific}

As with most LMIC, the 23 small LMIC in the Pacific Ocean have weak health research systems, limited human, infrastructure and financial resources in all disciplines compounded by geographical isolation and burgeoning population growth [14,32-35]. Many of these countries are not on track to achieve MDG 4 (reducing child mortality by two-thirds) and 5 (reducing maternal mortality by three-quarters) [36]. Three women die in the Pacific every day due a pregnancy related problem [37].

Pacific leaders in reproductive health decided at the 2007 meeting of the Pacific Society for Reproductive Health (PSRH) that member clinicians in the discipline are to be encouraged to perform clinical research and audit to improve local evidence in policy, service provision and as a way to address MDG 4 and 5. Research and audit workshops for clinicians commenced in 2009. The PSRH is a Charitable Trust registered in New Zealand with a membership of doctors, midwives, nurses and allied health professionals working in thirteen developing countries of the Pacific. The Building Reproductive health Research and Audit Capacity and Activity in the Pacific islands (BRRACAP) Study will assist the PSRH and policy makers in the Pacific region understand the impact of a RCB program aimed at clinicians and at improving reproductive health outcomes.

\section{Selection of countries}

Five Pacific Island countries - Vanuatu, Solomon Islands, Fiji, Samoa and Tonga - were selected and invited purposefully, and a sixth, Cook Islands, was included following a request from their health service. The five independent nations were chosen to represent the diversity of cultures, challenges and systems: Melanesian (Vanuatu, Fiji, Solomon Islands) and Polynesian (Samoa, Tonga) countries; populations that were more than 500,000 (Fiji, Solomon Islands) and smaller populations (Samoa, Vanuatu, Tonga); without a university (Tonga, Solomon Islands); with a medical school (Fiji, Samoa). The Micronesian group of Islands that are further north in the Pacific were not invited due to the anticipated high cost of participation. The Ministries of Health of five countries agreed to participate as a health 
service and a stakeholder. Discussions with the Fiji National University (FNU) led to their engagement replacing the need to engage the Fiji public health service.

\section{Research workshop}

The workshop incorporated 48 hours of seminars, lectures and small group work over 6 days. The content was devised with the aim to teach the basic components of clinical research and audit and included motivational talks aimed to inspire the participants to believe that doing research was possible even for those who had not done this previously. The participants from the same country were encouraged to work together as a team to develop projects they identified as priorities to their service. The program with listed faculty is attached (Additional file 1). The workshop was conducted in Auckland New Zealand to utilise the wealth of experienced Pacific researchers from various academic institutions especially from those at the University of Auckland.

\section{Research mentoring}

The participants were asked to nominate a preferred research mentor from a list of mentors, which included some of the faculty of the research workshop. All the sixteen research mentors who consented to participate are established researchers and all except five have Pacific research experience. The five mentors without Pacific experience were encouraged to liaise closely with the PI who became the co-mentor to their participants.

A Code of Mentorship for mentors and participants was adapted from Blixen [38] to guide the mentor-mentee relationship. It was not meant to be prescriptive and an informal mentoring relationship works better for adult learners [39]. A participatory action learning philosophy was encouraged where the mentor and participant learn from each other during the research journey. This was done by frequent email reminders to both mentors and participants to exchange ideas and thoughts about research progress, assistance, barriers, enablers and ideas.

The quality of mentoring and the performance of the participants will be evaluated at the conclusion of the formal part of program in August 2014, 18 months after inception.

The main aim therefore of the BRRACAP Study was to determine the impact of a RCB program on research activity amongst selected reproductive health clinicians in the participating countries. The secondary aim was to understand the characteristics of those clinicians who become research successful and the barriers to and enablers of clinical research in the Pacific Islands.

\section{Methods}

\section{Study participants}

The five Ministries of Health were invited to select five reproductive health clinician participants for the study.
Due to funding constraints, the Cook Islands health service was asked to provide only one participant. We assumed that five clinicians, made up of midwives, doctors and others, working on a clinical research or clinical audit project together would provide team support, different skills and enough members for task delegation, i.e. critical mass. Critical mass is the capacity required to execute collective research action and is dependent not only on numbers but the commitment, costs, and skill set of the individuals in the group. We planned that 26 participants from the six health services would attend the research workshop; which would be manageable in both class size and cost, and would provide an adequate sample to follow for two years even with minor attrition.

The requirements for the participants were: 1) an informed consent to participate; 2) active clinician (doctors, midwives, nurses and clinician managers) working in reproductive health; 3) must want to learn and do research/ clinical audit; and 4) preferably, be in a leadership role, a team player, have performed research, and a member of the Pacific Society for Reproductive Health (PSRH). All midwives in the Pacific were initially trained as nurses.

To inform the content of the workshop, a needs analysis survey of selected personnel was conducted using SurveyMonkey [40]. The invited personnel were Pacific stakeholders, reproductive health clinicians, research funding agencies in the region and selected researchers who had done research in the Pacific.

\section{Stakeholders}

The key stakeholders were the Ministries of Health in the five countries namely Vanuatu, Solomon Islands, Samoa, Tonga and the Cook Islands and the FNU. The other two key stakeholders were the PSRH and the Faculty of Medicine and Health Sciences of the University of Auckland. The former provided the mechanism and the umbrella under which the study could be performed and the latter as the provider of main faculty for the research workshop and the supervision and advice for the study.

\section{Employer's commitment}

The employers, through the managers of the services, agreed to support the participants with their research projects by funding airfares and stipends to the research workshop, allocating half a day a week for the participant to perform clinical research and audit activity and providing their participants with internet access for research.

Ethical approval was gained for this study from the University of Auckland Human Participants Ethics Committee (Ref. No. 8373).

\section{Data collection}

The RCB program was designed to follow a flow of interventions, tasks and objectives as in Additional file 2. 


\section{Mapping of research systems}

Senior representatives of the six countries were invited to complete the Mapping of Research Systems using the tool that was used by WHO and COHRED for mapping research systems in 15 Pacific countries in 2007 [41]. Five were completed prior to the research workshop in March 2013. The mapping aimed to assess the quality of each country's health research systems and how that compared to the 2007 review. It also served to understand the research culture in each country and how that would relate to the performance of their participants.

\section{Characteristics questionnaire}

All the participants were asked to complete a 'Characteristics Questionnaire' by the first day of the research workshop (Additional file 3). The questionnaire was developed using a slightly modified tool that was validated in in Australia [42] and made it applicable for the Pacific clinicians. The tool was tested using cognitive interviewing [43] of five clinicians. The questionnaire sought demographic professional and personal data that will inform of the participants' research experience, their current qualifications, work role and research expectations, and what they perceived to be barriers to and enablers of research in their setting. The questionnaire was piloted and could be completed comfortably within 30 minutes with responses collated thematically.

\section{Interviewer-administered questionnaire}

All the participants were interviewed by one of the three trained health-worker interviewers. The structured interviews were conducted face to face on the day before the workshop and lasted about 15 minutes each. The interview was semi-formal which the interviewer could elaborate if needed. It sought to understand the participant's current professional commitments, their organisational research culture, research experience, future research plans, and personal information that impacts on research effectiveness. A research skills test was performed that required some knowledge in using a Microsoft Excel spread sheet. The interview data also cross-checked the information gathered in the mapping and professional questionnaires. The questionnaire was piloted using cognitive interviewing methodology, interviews were audio-recorded, independently transcribed, content checked against original recording, offered to participants to review, and then analyzed using key response patterns and themes. Mixtures of deductive and inductive approaches were used to identify themes consistent with the question schedule embedded in the data. The data was coded and emerging themes were used to build a thematic framework, to which the participant responses were categorized [44].

\section{Focus groups}

Heads of departments, clinical managers and specialists were invited to two focus groups of which one was for the midwives (six midwives and one nurse) and one for the doctors (eight doctors). The focus group interviews were facilitated by one researcher (AE) over two evenings lasting 2 hours each and sought to obtain a consensus on how research performance should be measured in the two groups. The focus groups were designed to identify research outcomes that were important to the clinicians. These were audio-recorded, independently transcribed into verbatim script, offered to participants to review, then analyzed using key response patterns and themes [44].

A set of research indicators, or surrogate markers of research performance was developed by the groups and was then presented to the whole group for feedback. Further development was done before these were sent to all the stakeholders for comment and as part of continuing consultation. Maximum points were assigned by consensus to identified research outputs that were of most value to the participants and decreasing points to those research activities which were deemed of less value. The concept of points for an assigned professional activity was made easier by an elaboration on a continuous professional development points system most of the participants were familiar with.

\section{Pre-test and post-test}

The Pre and Post Test Questionnaires were similar and were designed to assess knowledge of research methodology and principles prior to and after the workshop. It also sought to explore their awareness of routinely collected data in their settings and how these can be analysed for information that can guide service delivery. The Post-Test Questionnaire had additional questions, which assessed attitude to research and was obtained from the work of Bates in Ghana [45]. This was in the form of short answers in an open text format and was piloted using cognitive questioning.

\section{Evaluation and feedback}

As well as daily reflections on the learning from the workshop topics obtained by interactive discussion, participants completed an evaluation questionnaire on the last day of the workshop.

\section{Group mentoring and social media}

Group mentoring is important for group learning so that the same advice to one participant or one question can be shared for the others learning [46]. The wisdom and experience of others is shared with the group [47]. Opportunities were created for group mentoring using social media in Facebook, Research Gate and Linked In. These platforms for group mentoring are in place although they 
have not been evaluated [47]. All participants and mentors were invited to join one or all three sites. Mentoring by email, Skype and by phone was also encouraged although email was considered cheaper. The study design and outcome measures are subject to change during the study as required by the participatory action learning process [48].

\section{Results}

This paper reports on the baseline results, which were captured from the Characteristics Questionnaire.

\section{Participants}

The 28 clinicians selected from the six participating $\mathrm{Pa}$ cific Island countries: Cook Islands (1), Fiji (8), Samoa (4), Solomon Islands (5), Tonga (5) and Vanuatu (5). A participant chosen by Tonga and who was studying in NZ had approved leave for only 2 days of the workshop.

Most of the participants were medical practitioners (17, $61 \%$ ) although most had various roles. Most had a postgraduate diploma or a Masters degree (23, $82 \%$ ) (Table 1). The age range of participants was 28 to 55 years of age with a median age of 40 . There were 20 women and 8 men.

\section{Confidence, experience and access}

Two (7\%) of the participants were 'not confident' to use a computer, 10 (36\%) were 'not confident' or 'less confident' to find a paper at the workplace and that $17(61 \%)$ were not confident to write a research protocol (Table 2). Of the 11 participants with Masters degrees, 5 (45\%) were 'not confident' to use a referencing software and the same proportion were 'not confident' to write a research proposal. Although $8(29 \%)$ had submitted a proposal to an Ethics Committee, only 2 (7\%) had written a publications in peer-reviewed journals when they were working in Australia and NZ (Table 3). Only 13 (43\%) of the participants had skills to use an Excel spread sheet (Table 4), which included 5 (45\%) of the 11 participants with Masters degrees. Of the 24 who were expected to perform research as part of their role, $11(46 \%)$ had access to a library, 10 (42\%) felt management was supportive and 9 had access to administrative assistance (Table 5).

Nineteen (68\%) had not published or presented a paper at a conference. Only two had presented more than once and only one had published more than one paper. Eighteen $(64 \%)$ were not performing any current research and three (11\%) had more than one current project.

All of the participants agreed or strongly agreed that research was needed and in their department and 27 felt the same for clinical audit. Eighteen (64\%) agreed or strongly agreed that research evidence was used to inform practice at their work.

All wanted to learn how to do audit however two participants did not want to learn to do research.
Table 1 Research workshop participants by profession, qualification and role descriptions $(N=28)$

\begin{tabular}{lll}
\hline Characteristics of participants & N & \% \\
\hline Profession & 8 & 29 \\
Midwife & 1 & 4 \\
Nurse & 8 & 29 \\
Obstetrician gynaecologist & 9 & 32 \\
Medical doctor & 2 & 7 \\
Other & & \\
Qualification & 5 & 18 \\
Basic/minimum registrable qualification & 12 & 43 \\
Postgraduate diploma & 11 & 39 \\
Postgraduate masters & & \\
Roles (each participant may have more than one) & 6 & 21 \\
Academic & 24 & 86 \\
Patient care & 20 & 71 \\
Teaching & 24 & 86 \\
Supervision & 18 & 64 \\
Administration & 24 & 86 \\
Research as part of role & &
\end{tabular}

\section{Barriers and motivators for research}

Nearly all the participants identified time constraints as a barrier to performing research although the lack of research coordination, funding and skills also featured highly (Table 6).

Motivators for doing research were to develop skills, mentor availability and solving problems.

\section{Discussion}

\section{The BRRACAP program}

Only a few RCB programs have targeted clinicians and our study is the first prospective study to provide a $\mathrm{RCB}$ program, which includes research training and mentorship to a large number of clinicians from LMIC in the Pacific. It was important to collaborate with key stakeholders, as there were resource implications and responsibilities for staff support on their return home from training.

Our study was well supported by the health services of the five Pacific LMIC, the Dean of FNU and funders. Development partners and governments understand the importance of developing research capacity in LMIC as a pre-requisite to improving health outcomes [13,49-52] and addressing the gaps in MDG 4 and 5 [53]. However, most of the 19 recommendations from a WHO sponsored RCB workshop in the Pacific in 2007 [35] have not been implemented with most countries in the region continuing to have workforce challenges [54] and weak health research systems [14].

Pacific values of reciprocity, collectivity, respect, generosity, importance of relationships as they relate to the 
Table 2 Level of confidence in various tasks and skills $(\mathbf{N}=\mathbf{2 8})$

\begin{tabular}{|c|c|c|c|c|c|}
\hline Skills scale & $\begin{array}{c}\text { Not confident } \\
(0-2) \\
\end{array}$ & $\begin{array}{c}\text { Less confident } \\
(3-4)\end{array}$ & $\begin{array}{c}\text { Confident } \\
(5-6)\end{array}$ & $\begin{array}{c}\text { Very confident } \\
(7-8) \\
\end{array}$ & $\begin{array}{c}\text { Extremely } \\
\text { confident }(9-10)\end{array}$ \\
\hline Using a computer referencing system & $11(39 \%)$ & $5(18 \%)$ & $6(21 \%)$ & $3(11 \%)$ & $3(11 \%)$ \\
\hline Writing a research protocol & $10(36)$ & $7(25)$ & $2(7)$ & $9(32)$ & 0 \\
\hline Providing advice to less experienced researchers & $9(32)$ & $6(21)$ & $5(18)$ & $6(21)$ & $2(7)$ \\
\hline Reading a paper critically & $8(29)$ & $4(14)$ & $7(25)$ & $6(21)$ & $3(11)$ \\
\hline Finding a paper at workplace & $7(25)$ & $3(11)$ & $6(21)$ & $7(25)$ & $5(18)$ \\
\hline Using a word processing software & $2(7)$ & $1(4)$ & $6(21)$ & $4(14)$ & $15(54)$ \\
\hline Using a computer to write a letter & $2(7)$ & 0 & $3(11)$ & $3(11)$ & $20(71)$ \\
\hline
\end{tabular}

various Pacific Research Methodologies was emphasised at the workshop. This was seen central to strengthening capacity across very diverse social, cultural, language, historical, axiological, ontological and epistemological standpoints of Pacific Islanders. Some of the Pacific research frameworks such as the Talanoa [55] and Faafaletui [56] frameworks, encapsulates Pacific values and traditions using cross-cultural storytelling and perspectives derived from Pacific traditions and values. The participants were encouraged to consider these frameworks in their research work and to be aware of the "importance of carrying out research alongside their day-to-day duties" [33].

The framework of the RCB program was guided by research evidence that training of clinicians as researchers require didactic training in core topics and clinical research methods $[20,57,58]$ supported by an enhancing environment of collaborations [31,59] and appropriate mentorship $[26,27,38]$. We endeavoured to provide these essential elements of RCB within the constraints of time, funding, distant mentoring and the barriers at the participants' home environment.

Table 3 Research skills $(\mathbf{N}=\mathbf{2 8})$

\begin{tabular}{lll}
\hline & N & $\%$ \\
\hline Obtained research funding & 2 & 7 \\
Written a publication in a peer-reviewed journal & 2 & 7 \\
Had clinical audit training & 5 & 18 \\
Analysed qualitative data & 7 & 25 \\
Submitted an ethics application & 8 & 29 \\
Written a letter or an article in any local publication & 10 & 36 \\
Had research training & 13 & 46 \\
Analysed quantitative data & 13 & 46 \\
Written a research report & 14 & 50 \\
Integrated research findings into every day practice & 14 & 50 \\
Designed a questionnaire & 19 & 68 \\
Used a computer data management system & 24 & 86 \\
Collected data & 26 & 93 \\
\hline
\end{tabular}

\section{The results}

The 28 reproductive health clinicians, selected by their managers or employers, came from varying educational and professional backgrounds. It was important in this first study, to observe the impact of a RCB program on a range of clinicians including nurses. Whereas the few RCB programs have targeted medical doctors, who were well represented in our study $(17,61 \%)$, there is a need to develop nurse-led research in LMIC [60]. Nine (33\%) nurses were selected of which three were from the FNU and the others were leading midwives in their services.

Selection criteria were agreed with the employers and on face value, the 28 participants were highly regarded reproductive health clinicians as reflected by the fact that 23 of them had a postgraduate Diploma or Masters qualification. However, it was concerning that $3(11 \%)$ were not confident in using a word processing software, 15 (44\%) did not know how to use an Excel spreadsheet and two nurses did not want to learn how to do research. The selection of staff for overseas workshops from the Pacific Islands can be challenging as there is a skills shortage, therefore the selection takes other factors into account and tend to favour those in senior management, who view a funded trip as a work reward (Wame Baravilala, personal communication). Although there are no clear criteria for selection of clinicians for research training, the WHO Training in Tropical Diseases Research Program have selected "young and talented scientists" who submit acceptable research proposals [30]. Attaining higher research training however does not guarantee satisfactory research output [61].

\begin{tabular}{lcc}
$\begin{array}{l}\text { Table } \mathbf{4} \text { Observed level of skill using a MS Excel } \\
\text { spreadsheet }\end{array}$ & $\mathbf{N = \mathbf { 2 8 }}$ \\
\hline Skills assessment & 1 & $\mathbf{\%}$ \\
\hline Extremely skilled & 9 & 0 \\
Very skilled & 3 & 32 \\
Skilled & 3 & 11 \\
Not skilled & 12 & 11 \\
Extremely not skilled & & 43 \\
\hline
\end{tabular}


Table 5 Research part of job and have access to $(N=24)$

\begin{tabular}{lll}
\hline & N & \% \\
\hline Library & 11 & 46 \\
Management support & 10 & 42 \\
Administrative assistance & 9 & 36 \\
Software & 7 & 29 \\
Experienced researcher & 6 & 25 \\
Equipment & 6 & 25 \\
Regular research/audit meetings & 6 & 25 \\
Research office & 5 & 21 \\
Supervision & 4 & 17 \\
Funding & 4 & 17 \\
\hline
\end{tabular}

A third of the participants were nurses and it is essential to monitor the impact of educational interventions on this important workforce despite the observation that more research publications were authored by doctors rather than by nurses [14]. Important factors that limit nurse participation in research are a lack of access to research training and infrastructure compared to doctors including hierarchies of power among disciplines [60]. An increase in research by nurses would improve the quality of nursing care through an increase in evidence utilization [62]. Educational needs, motivators and barriers for research may be different for nurses.

Although 26 had collected data (Table 3) only 13 (46\%) can use basic functions of an Excel spreadsheet and the same number have analysed qualitative data. Twelve (43\%) were not confident to read research articles critically and
17 (61\%) were not confident in writing a research proposal. Despite 24 (86\%) clinicians being required to perform research as part of their employment, only 11 (46\%) had access to a library and 6 (25\%) to an experienced researcher. Conversely, with limited research resource, more barriers and fewer enablers in the Islands, publication output is stifled despite 6 (25\%) of those expected to perform research recording access to an experienced researcher. Of the 6,3 were nurses and the other three were junior medical staff and they often view their consultant specialists as experienced researchers. Seven of the eight specialists had not published or lead a research program. This confirms previous findings that research in the Pacific is hampered by not only a lack of research infrastructure but by the lack of clinicians with research skills and knowledge that is required to perform research $[14,33,35]$. It also showed a weakness in the specialist training curriculums in the Pacific.

The participants other roles expected of them as leaders of their departments and teams pose time constraints on research activity with 27 (96\%) (Table 6) identifying time constraints as a major barrier as other RCB studies have identified [63,64]. We requested of the participants' employers that half a day a week per allocated for research and audit activity. There is evidence however that clinicians may fill this time with clinical work as they are more comfortable in doing that than research [26]. Other significant barriers were the lack of skills $(20,71 \%)$ and lack of administration support $(18,64 \%)$, which was the reason why it was requested that the employers provide support to their researchers. Addressing the barriers may require

Table 6 Barriers and motivators to performing research $(n=28)$

\begin{tabular}{|c|c|c|c|c|c|}
\hline Barriers & Yes & $\%$ & Motivators & Yes & $\%$ \\
\hline Time constraints & 27 & 96 & Develop skills & 25 & 89 \\
\hline No coordination & 22 & 79 & Mentors available & 24 & 86 \\
\hline No funding & 20 & 71 & Problem identified and needs changing & 22 & 79 \\
\hline Lack of skills & 20 & 71 & Keep brain stimulated & 21 & 75 \\
\hline Lack of administration support & 18 & 64 & Increase satisfaction & 20 & 71 \\
\hline Lack of software & 18 & 64 & Link to university & 20 & 71 \\
\hline Lack of backfill & 16 & 57 & Career advancement & 19 & 68 \\
\hline Fear of research language & 14 & 50 & Opportunity to participate at own level & 19 & 68 \\
\hline Lack of support from management & 14 & 50 & Colleagues doing research & 18 & 64 \\
\hline Prefer work life balance & 14 & 50 & Grant funding & 18 & 64 \\
\hline Equipment & 14 & 50 & Formal part of postgraduate study & 17 & 61 \\
\hline Other personal commitment & 12 & 43 & Encouraged by managers & 16 & 57 \\
\hline Fear of getting it wrong & 9 & 32 & Desire to prove a theory & 16 & 57 \\
\hline Isolation & 8 & 29 & Dedicated time to research & 15 & 54 \\
\hline \multirow[t]{3}{*}{ Not interested in research } & 7 & 25 & Study or research scholarship & 15 & 54 \\
\hline & & & Research written into role description & 13 & 46 \\
\hline & & & Other & 13 & 46 \\
\hline
\end{tabular}


modest resources but will be the price for a research-aware, if not a research-skilled workforce. Surrogate markers of research developed by the group will assist in assessing the participants progress with their research objectives.

The commonest motivating factors for the participants were the development of research skills $(25,89 \%)$ and the availability of mentors (24,86\%). Research skills and knowledge have traditionally been delivered to clinicians as postgraduate courses such as a Masters degree or in a workshop format such as the one designed for this study $[17,45,65]$. Other modes of delivery such as video linking [66] and in-service training were found effective [67] but were deemed not suitable or possible for this study. The mentoring program was designed to be responsive to the participants needs. Most of the participants would need significant assistance with their identified research or audit projects so the experienced research mentors of their choice was considered preferable. Most of the mentoring will be by email and online and this has been shown to be effective in other settings [68]. The creation of mentoring on social media to provide group learning may provide another opportunity for research support with the knowledge that those with limited internet access may not be served by this medium.

Strengths of our study include the broad range of clinicians selected, the enthusiasm of the Ministries of Health to participate and the participants to learn. The limitation of the study was the uncertainty in selection criteria that resulted in the selection of two participants who did not want to learn research and the severe limitation in knowledge and skills of some, which may hamper their learning of basic research principles. In addition, the participants needed individualised and local intensive mentoring so a participatory action learning (PAL) and supportive local environment can be provided. The PAL methodology would have been suitable for this study [69] and has been used successfully in two areas of the Pacific [70,71] although long term research outputs and outcomes were not measured.

\section{Conclusion}

Fewer than five studies have published primary data describing RCB programs for clinicians in LMIC and a need was identified to improve reproductive health outcomes in the Pacific Islands. Training and supporting frontline clinicians to perform health research and audit and organising a RCB program across the diversity of small Pacific Island states with different cultures, capacities, priorities, resources and systems was challenging. The success in launching this RCB program depended on the collaboration and support of key stakeholders in the six Pacific states and the region.

The selected clinicians were a mixed group and besides the workshop training given, all will require individualized intensive mentoring and other support, tailored for research or audit projects that are closer to their area of clinical knowledge and expertise. It will be unrealistic to expect all the participants to perform major research tasks but if a number of important barriers and enablers of research, which were identified were addressed and cultivated respectively, then the participants may, with adequate mentorship, increase research and audit activity and build research capacity in the six Pacific Islands.

This paper describes the methods, rationale and baseline findings for the BRRACAP Study. Through detailed exploration of personal, professional and environmental factors that impact on research performance, our findings suggest that this RCB program has the potential to lead to a better understanding of personal and professional factors that may inform RCB programs in the future. Further findings from this RCB program will be reported in future publications.

\section{Additional files}

\section{Additional file 1: Research Workshop Program.}

Additional file 2: Interventions, Tasks and Objective of the BRRACAP Study.

Additional file 3: Professional and Personal Characteristics' questionnaire.

\section{Competing interests}

The authors declare that they have no competing interests.

\section{Authors' contributions}

AE participated in the conception, design and coordination of the study, performed the literature search, data collection, analysis and drafted the manuscript. TK participated in the design of the study, performed the literature search, conducted review and helped to edit the manuscript. BS participated in the conception of the study, assisted with study design and helped edit the manuscript. LM participated in the design of the study and helped to edit the manuscript. AH participated in the conception of the study, assisted with study design and helped edit the manuscript. All authors read and approved the final manuscript.

\section{Acknowledgement}

We thank the World Health Organization (Vanuatu Office), the United Nations Fund for Population \& Development (Solomon Is office), Australian Aid via the Specialised Clinical Services in the Pacific Islands and the Pacific Health Research \& Development Foundation Trust for funding the research workshop.

\section{Author details}

'South Auckland Clinical Campus, University of Auckland, Middlemore Hospital, Auckland, New Zealand. ${ }^{2}$ Office of Medical Education, Faculty of Medicine, University of New South Wales, Sydney, NSW, Australia.

${ }^{3}$ Department of Obstetrics and Gynaecology, University of Auckland, Auckland, New Zealand.

Received: 6 October 2013 Accepted: 12 June 2014

Published: 19 June 2014

\section{References}

1. Maher D, Biraro S, Hosegood V, Isingo R, Lutalo T, Mushati P, Ngwira B, Nyirenda M, Todd J, Zaba B, on behalf of the ALPHA network: Translating global health research aims into action: the example of the ALPHA network. Trop Med Int Health 2010, 15(3):321-328. 
2. World Health Organization: WHO's role and responsibilities in health research. In Geneva 2010 [http:// www.who.int/gb/ebwha/pdf_files/EB124/ B124_12-en.pdf]

3. Travis P, Bennett S, Haines A, Pang T, Bhutta Z, Hyder AA, Pielemeier NR, Mills A, Evans T: Overcoming health-systems constraints to achieve the Millennium Development Goals. Lancet 2004, 364(9437):900-906.

4. Benjamin A: Audit: how to do it in practice. BJOG 2008, 336:1241-1245.

5. White F: Capacity-building for health research in developing countries: a manager's approach. Rev Panam Salud Publica 2002, 12(3):165-72.

6. Patel V, Kim Y-R: Contribution of low- and middle-income countries to research published in leading general psychiatry journals, 2002-2004. Br J Psychiatry 2007, 190:77-78.

7. Aaserud M, Lewin S, Innvaer S, Paulsen EJ, Dahlgren AT, Trommald M, Duley L, Zwarenstein M, Oxman AD: Translating research into policy and practice in developing countries: a case study of magnesium sulphate for pre-eclampsia. BMC Health Serv Res 2005, 5:68

8. WHO: Everybody's Business: Strengthening Health Systems to Improve Health Outcomes: Who's Framework for Action. In Geneva: World Health Organisation; 2007.

9. Lansang MA, Alejandria M, Banzon E, Castillo-Carandang N, Juban N: A rapid situational analysis of health policy and systems research in the western pacific region. In Manila: A technical report submitted to the World Health Organization, Western Pacific Regional Office Manila, Philippines; 2009.

10. Adam T, Ahmad S, Bigdeli M, Ghaffar A, Rottingen J-A: Trends in health policy and systems research over the past decade: still too little capacity in low-income countries. PLOS ONE 2011, 6(11):e27263.

11. Kellerman R, Klipstein-Grobusch K, Weiner R, Wayling S, Fonn S: Investing in African research training institutions creates sustainable capacity for Africa: the case of the University of the Witwatersrand School of Public Health masters programme in epidemiology and biostatistics. Health Res Policy Syst 2012, 10(1):11-17.

12. Mwaba P, Bates M, Green C, Kapata N, Zumla A: Research capacity strengthening in African countries. Lancet 2010, 375(9729):1874.

13. Bates I, Akoto AYO, Ansong D, Karikari P, Bedu-Addo G, Critchley J, Agbenyega T, Nsiah-Asare A: Evaluating health research capacity building: an evidence-based tool. PLoS Med 2006, 3(8):1224-1229.

14. Ekeroma AJ, Pollock T, Kenealy T, Shulruf B, Sopoaga F, Montorzi G, McCowan $L$, Hill A: Pacific island publications in the reproductive health literature 2000-2011: with New Zealand as a reference. ANZJOG 2013, 53(2):197-202. doi:10.1111/ajo.12039.

15. Hydén G: University and faculty research funds at universities in Mozambique, Tanzania and Uganda. In Stockholm: Swedish International Development Cooperation Agency; 2006 [http://www.sida.se/Publications/ Import/pdf/sv/0623-University-and-Faculty-Research-Funds-at-Universities-inMozambique-Tanzania-and-Uganda_2046.pdf]

16. Kitua AY, Corrah T, Herbst K, Nyirenda T, Agwale S, Makanga M, Mgone CS: Strengthening capacity, collaboration and quality of clinical research in Africa: EDCTP Networks of Excellence. Tanzan J Health Res 2009, 11(1):51-54.

17. Goto A, Vinh NQ, Van NTT, Phuc TH, Minh PN, Yasumura S, Khue NT: Developing a public health training and research partnership between Japan and Vietnam. Int Electron J Health Educ 2007, 10:19-26.

18. Thomas $P$, While $A$ : Increasing research capacity and changing the culture of primary care towards reflective inquiring practice: the experience of the West London Research Network (WeLReN). J Interprof Care 2001, 15(2):133-139.

19. Ranson K, Law TJ, Bennett S: Establishing health systems financing research priorities in developing countries using a participatory methodology. Soc Sci Med 2010, 70(12):1933-1942.

20. Goto A, Nguyen TN, Nguyen TM, Hughes J: Building postgraduate capacity in medical and public health research in Vietnam: an in-service training model. Public Health 2005, 119(3):174-183.

21. DePaolo LV, Leppert PC: Providing research and research training infrastructures for clinical research in the reproductive sciences. Am J Obstet Gynecol 2002, 187(4):1087-1090.

22. Kahn K, Ryan G, Beckett M, Taylor S, Berrebi C, Cho M: Bridging the gap between basic science and clinical practice: a role for community clinicians. Implement Sci 2011, 6(34): [http://www.implementationscience.com/content/6/1/34]

23. Craik J, Rappolt S: Enhancing research utilization capacity through multifaceted professional development. Am J Occup Ther 2006, 60:155-164.

24. Page J, Heller RF, Kinlay S, Lim LLY, Qian W, Suping Z, Kongpatanakul S, Akhtar M, Khedr S, Macharia W: Attitudes of developing world physicians to where medical research is performed and reported. BMC Public Health 2003, 3:6.

25. Hill A: Building Research Teams. In BRRACAP Study Workshop. Auckland New Zealand: PSRH; 2013.

26. Birden $\mathrm{HH}$ : The researcher development program: how to extend the involvement of Australian general practitioners in research? Rural Remote Health 2007, 7(3): [http://www.ncbi.nlm.nih.gov/pubmed/17696757]

27. Curtis P, Dickinson P, Steiner J, Lanphear B, Vu K: Building capacity for research in family medicine: is the blueprint faulty? Fam Med 2003, 35(2):124-130.

28. Harding KE, Stephens D, Taylor NF, Chu E, Wilby A: Development and evaluation of an allied health research training scheme. J Allied Health 2010, 39(4):e143-e148.

29. Lowe B, Hartmann M, Wild B, Nikendei C, Kroenke K, Niehoff D, Henningsen $P$, Zipfel $S$, Herzog W: Effectiveness of a 1-year resident training program in clinical research: a controlled before-and-after study. J Gen Intern Med 2008, 23(2):122-128.

30. Nchinda TC: Research capacity strengthening in the South. Soc Sci Med 2002, 54(11):1699-1711.

31. Cooke J, Susan A, Booth A, Wilkinson N: Re:Cap - identifying the evidence- base for research capacity development in health and social care. In Trent Research. Edited by Literature ASRot, Commissioned by the National Coordinating Centre for Research Capacity Development icwtNRaDSUNSG. University of Sheffield; 2006.

32. Anderson I, Crengle S, Leialoha Kamaka M, Chen TH, Palafox N, Jackson-Pulver L: Indigenous health in Australia, New Zealand, and the Pacific. Lancet 2006, 367(9524):1775-1785.

33. Cuboni HD, Finau SA, Wainiqolo I, Cuboni G: Fijian participation in health research: analysis of Medline publications 1965-2002. Pac Health Dialog 2004, 11(1):59-78.

34. Kane P: Priorities for reproductive health: assessing need in the older population in the Asia-Pacific region. Medscape Womens Health 2001, 6(4):2.

35. WHO Report: Consultation on strengthening health research capacity in the Pacific. In Nadi, Fiji; 2007. [Accessed 17 August 2012] From URL: http:// www.wpro.who.int/health_research/documents/docs/ Meetingreport_Nadi2007.pdf.

36. Morrow M, Dayal P, Zhen J, Luke G, Gopalakrishnan A, Ndwala S: Reducing maternal, newborn and child deaths. In Australia: World Vision, Nossal Institute for Global Health; 2008:29.

37. New Zealand Parliamentary Group on Population and Development: Making Maternal Health Matter. In Wellington; 2010 [http://www.fwrsmi. org.fj/files/Making\%20MH\%20Matter(1).pdf]

38. Blixen CE, Papp KK, Hull AL, Rudick RA, Bramstedt KA: Developing a mentorship program for clinical researchers. J Contin Educ Health Prof 2007, 27(2):86-93.

39. Daloz LA: Mentor: Guiding the Journey of Adult Learners. John Wiley \& Sons Inc: San Francisco; 2012.

40. Wright KB: Researching internet-based populations: advantages and disadvantages of online survey research, online questionnaire authoring software packages, and Web survey services. J Comput-Mediat Commun 2005, 10(3):00-00

41. Kennedy A, IJsselmuiden C: National Health Research Systems NHRS Mapping Questionnaire. In Geneva: Council on Health Research for Development; 2006 [http://www.cohred.org/downloads/open_archive/ Pacific\%20lslands\%20NHRS\%202009_WHO_COHRED_HRCP.pdf]

42. Pager $\mathrm{S}$, Holden L, Golenko X: Motivators, enablers, and barriers to building allied health research capacity. J Multidiscip Healthc 2012, 5:53-59.

43. Presser S, Rothgeb J, Couper Mea: Methods for testing and evaluating survey questions. New Jersey: John Wiley \& Sons; 2004.

44. Spencer L, Ritchie J, O'Conner W: Qualitative research practices: a guide for social science students and researchers. New York: Sage; 2003.

45. Bates I, Ansong D, Bedu-Addo G, Agbenyega T, Akoto AY, Nsiah-Asare A, Karikari P: Evaluation of a learner-designed course for teaching health research skills in Ghana. BMC Med Educ 2007, 7:18.

46. Scott ES, Smith SD: Group mentoring: a transition-to-work strategy. J Nurses Staff Dev 2008, 24(5):232-238.

47. Huizing RL: Mentoring together: a literature review of group mentoring. Mentoring Tutoring: Partnersh Learn 2012, 20(1):27-55.

48. Marsick VJ, O’Neil J: The many faces of action learning. Manag Learn 1999, 30(2):159-176 
49. Council on Health Research for Development: Are international health research programmes doing enough to develop research systems and skills in low and middle income countries? Geneva: COHRED; 2007. [Accessed 16 July 2012] From URL: http://www.cohred.org/wp-content/ uploads/2013/08/4.ResponsibleVerticalProgrammingLOWRES.pdf.

50. Pang T, Terry RF: WHO/PLoS collection "No health without research": a call for papers. PLoS Med 2011, 8(1):e1001008.

51. White F: Capacity-building for health research in developing countries: a manager's approach. Pan Am J Public Health 2002, 12(3):165-172.

52. Pastrana T, Vallath N, Mastrojohn J, Namukwaya E, Kumar S, Radbruch L, Clark D: Disparities in the contribution of Low- and middle-income countries to palliative care research. J Pain Symptom Manage 2010, 39(1):54-68.

53. Bennett S, Ssengooba F: Closing the gaps: from science to action in maternal, newborn, and child health in Africa. PLOS Med 2010, 7(6):e1000298. doi:1000210.1001371/journal.pmed.1000298.

54. Raman S, Ekeroma A, Horner J, Mola G, Roberts G: Australia and New Zealand's support for skilled health workfroce in maternal, newborn and child health in the Pacific. Pac Health Dialog 2012, 16(2):146-153.

55. McGrath B, Ka'ili T: Creating Project Talanoa: a culturally based community health program for U.S. Pacific Islander adolescents. Public Health Nurs 2010, 27(1):17-24.

56. Suaalii-Sauni T, Wheeler A, Saafi E, Robinson G, Agnew F, Warren H, Erick M, Hingano T: Exploration of pacific perspectives of pacific models of mental health service delivery in New Zealand. Pac Health Dialog 2009, 15(1):18-27.

57. Harrington R, Califf R, Hodgson P, Peterson E, Roe M, Mark D: Careers for clinician investigators. Circulation 2009, 119:2945-2950.

58. Back SE, Book SW, Santos AB, Brady KT: Training physician-scientists: a model for integrating research into psychiatric residency. Acad Psychiatry 2011, 35(1):40-45.

59. Cole D, Kakuma R, Fonn S, Izugbara C, Thorogood M, Bates I: Evaluations of health research capacity strengthening: a review of the evidence. In 2012.

60. Edwards N, Webber J, Mill J, Kahwa E, Roelofs S: Building capacity for nurse-led research. Int Nurs Rev 2009, 56(1):88-94.

61. Hyder A, Akhter T, Qayyyum K: Capacity development for health research in Pakistan: the effects of doctoral training. Health Policy Plan 2003, 18(3):338-343.

62. Corchon S, Portillo MC, Watson R, Saracibar M: Nursing research capacity building in a Spanish hospital: an intervention study. J Clin Nurs 2011, 20(17-18):2479-2489.

63. Barnett L, Holden L, Donoghue D, Passey M, Birden HH: What's needed to increase research capacity in rural primary health care? Aust J Prim Health 2005, 11(3).

64. Lee G, Metcalf S: Building research capacity: through a hospital-based clinical school of nursing. Nurse Educ Today 2009, 29(3):350-356.

65. Ajuwon AJ, Kass N: Outcome of a research ethics training workshop among clinicians and scientists in a Nigerian university. BMC Med Ethics 2008, 9:1.

66. Ferrelli R, Serrano CR, Balladelli PP, Cortinois A, Quinteros J: Strengthening local health care management in Bolivian districts through participatory operational research. Int J Health Plann Manag 1997, 12(1):29-50

67. Dodani S, Kazmi KA, Laporte RE, Wilson JP: Effectiveness of research training workshop taught by traditional and video-teleconference methods in a developing country. [Retraction in Glob Public Health. 2010;5(1):113; PMID: 19890759]. Glob Public Health 2009, 4(1):82-93.

68. Singh G: We write better together: E-mentoring to induct developing country researchers into scientific literacy practices. In Geneva; 2010.

69. Woodward WR, Hetley RS: Diffusion, decolonializing, and participatory action research. Integr Psychol Behav Sci 2007, 41(1):97-105. discussion 114-109.

70. Redman-Maclaren ML, Maclaren DJ, Solomon J, Muse A, Asugeni R, Harrington H, Kekuabata E, Speare R, Clough AR: Research workshop to research work: initial steps in establishing health research systems on Malaita, Solomon Islands. Health Res Policy Syst 2010, 8:33.

71. Bailey J, Veitch C, Crossland L, Preston R: Developing research capacity building for Aboriginal \& Torres Strait Islander health workers in health service settings. Rural Remote Health 2006, 6(4):556.

doi:10.1186/1472-6920-14-121

Cite this article as: Ekeroma et al:: Building reproductive health research and audit capacity and activity in the pacific islands (BRRACAP) study: methods, rationale and baseline results. BMC Medical Education 2014 14:121.

\section{Submit your next manuscript to BioMed Central and take full advantage of:}

- Convenient online submission

- Thorough peer review

- No space constraints or color figure charges

- Immediate publication on acceptance

- Inclusion in PubMed, CAS, Scopus and Google Scholar

- Research which is freely available for redistribution 